\title{
A Jurisprudência Clássica Romana \\ e a Construção de um Direito Negocial fundado na Fides ${ }^{\star}$
}

\author{
Maren Guimarães Taborda
}

Procuradora do Município de Porto Alegre. Professora de História do Direito e de Direito Romano na PUCRS e na UNISINOS.

Mestre em Teoria do Direito e do Estado pela UFRGS.

"O melhor que obtemos da história é o entusiasmo que suscita" Goethe, Máximas e Reflexões

SUMÁRIO:

INTRODUÇÃO

I- A CONSTITUIÇÃOdOIUS ATRAVÉSDA SOBERANIA POPULAR: ENTREAUCTORITAS E POTESTAS

A - A lex publica e a Auctoritas dos juristas

$\mathrm{B}-\mathrm{O}$ método da interpretatio iuris

$\mathrm{C}-\mathrm{O}$ edito $\mathrm{e}$ as fórmulas processuais.

II- FORMULAÇÃO,INTERPRETAÇÃOE APLICAÇÃO DO DIREITO PELOOFFICIUM DO PRETOR E DAARS DOS JURISCONSULTOS.

A - O ius é uma prudentia e uma ars;

B - A extensão do ius civile aos estrangeiros através do officiium do pretor;

C-Ius Gentium e Ius Naturale.

CONCLUSÃO

\section{Introdução}

Há milênios o direito é uma técnica social específica de resolver conflitos concretos, isto é, regulação histórico-objetiva da vida so-

cial, e, desde o primeiro século de nossa era, recebeu uma forma que podemos chamar de 'científica’, por meio da obra dos jurisconsultos

* Versão integral da comunicação apresentada na 55" Sessão da Sociedade "Fernand de Visscher" para a História dos Direitos da Antiguiidade - SIHDA 2001, realizada em Rotterdam, Holanda, de 18 a 22 de setembro de 2001. 

teratura jurídica. Procurando encontrar as solue, via de conseqüência, não teria sobrevivido à

Denominada de 'jurisprudência clássi- romanos, que, com uma preocupação harmonizadora, guiando-se pela associação de idéias e usando continuamente o raciocínio por gênero e espécie, chegaram a certas noções de caráter geral, como a aequitas, a bona fides e o animus, produzindo, pela primeira vez, uma lições nas circunstâncias de casos que apresentavam a mesma característica específica, os jurisprudentes romanos justificavam suas decisões pelo fato de que eram razoáveis do ponto de vista prático ou diante das circunstâncias concretas ou, ainda, porque a elas tinham chegado por meio da analogia ou, ao inverso, pelo uso do argumento a contrario, nos casos opostos. Não fosse esse labor de aplicação do método das ciências naturais à jurisprudência, o direito romano não teria sido mais do que uma prática, uma arte empírica de regular processos, civilização romana. ${ }^{1}$ ca' ou 'direito romano clássico', esta literatura, transmitida ao Ocidente pela compilação justinianéia, forma, juntamente com o cristianismo e a filosofia grega, a base espiritual da cultura ocidental, sendo mais especificamente o alfabeto e a gramática da linguagem jurídica e da ciência do direito de base romanista. Por conseguinte, na mesma medida em que um matemático em formação não pode desconhecer a teoria pitagórica dos números; um filósofo, a filosofia dos gregos, e um médico, a anatomia e a fisiologia humanas, o jurista continental (principalmente o jusprivatista) não pode prescindir do estudo do direito romano clássico, a não ser que não queira ser jurista mas tão-somente um

"leitor e aplicador de leis". Ademais, se a metodologia jurídica contemporânea - a meditação sobre as bases, os fundamentos, a justificação e o modo de operar do direito - discute se este é uma "ciência" porque "sistemático"; uma "arte", porque "tópico"; uma "hermenêutica"; um "sistema de regras"; um "sistema de regras e princípios"; uma "razão prática"ou uma "prudência", o estudo do direito romano clássico (a par do interesse histórico, sempre presente) pode fornecer uma lição de experiência, educando o jurista moderno para uma correta compreensão de seu campo de saber e de seu papel social. Além disso, ao desmistificar o pensamento que identifica todo direito à lei, o estudo da jurisprudência clássica romana conscientiza o jurista da função constitutiva, sempre criadora, da jurisprudência, educando-o, igualmente, para o casuísmo científico, de modo que possa criar normas adequadas para casos concretos não previstos nas normas existentes. Com base nestas premissas, este estudo procura compreender, em linhas gerais, a rigorosa técnica dos jurisprudentes romanos na produção, interpretação e aplicação do direito, isto é, a metodologia segundo a qual foram criadas figuras jurídicas, formulados princípios doutrinais e regras jurídicas e consagrada uma terminologia que permanece em nossas legislações. Assim, a primeira parte trata da constituição do ius através da soberania popular ou da tensão entre auctoritas e potestas(I). A segunda parte trata da formulação, interpretação e aplicação do direito por meio do officium do pretor e da ars dos jurisconsultos e, mais especificamente, da construção de um direito negocial baseado na fides, o ius gentium (II). 1984, pp. 280 a 295; D'ORS, Álvaro. Derecho Romano Privado. Pamplona: EUNSA, 1997, pp. 57 a 63 ; VILLEY, Michel. Le Droit Romain. Coleçãa "que sais-je? Paris: Presse Universitaire de France, 9. ed., 1993, pp. 36 a 49; KASER, Max. Sur la Méthode des Jurisconsultes Romains. In: Romanitas. Revista de Cultura

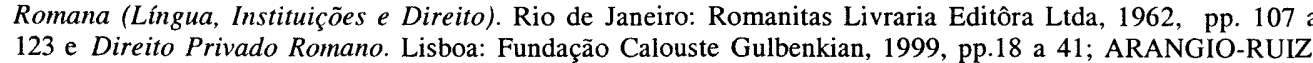
Vicente. Historia del Derecho Romano. Madrid: Editorial Reus, 1994, pp.326 a 368; KUNKEL, Wolfgang Historia del Derecho Romano. Barcelona: Ariel, 1991, pp. 108 a 118 e SCHULZ, Fritz. Princípios del Derecho
Conforme, principalmente: CRUZ, Sebastião. Direito Romano (Ius Romanum). Tomo I. $4^{2}$ ed. Coimbra: Romano. Madrid: Civitas, 1990, pp. 39 a 87.
I - A Constituição do Ius através da Soberania Popular: en-

$\mathrm{Na}$ experiência jurídica romana, o conceito de ius ${ }^{2}$ foi desenvolvido com base em problemas de forma e substância de ações, denotando uma clara hegemonia da formulação processual, uma vez que ius era, inicialmente, a ação: o que podia ser exigido pela força com a aprovação dos responsáveis pela manutenção dos princípios jurídicos que regiam a vida da comunidade. Ius é fundamentalmente uma vis (força) e nela se apóia porque, em sua formulação arcaica, o ius é uma ordem de poderes pessoais, que se manifesta em atos de força formal-

mente ritualizados. A todos imposto ou declarado, ius é o ato de violência privada que a sociedade reconhece como ordenado e adequado às circunstâncias, de modo que, ao final de uma ação, o cidadão se via investido de autorização para agir contra outrem, na defesa de seus interesses ou de suas posições (status) ou, ainda, para compensar uma ofensa sofrida. ${ }^{3}$ De dois arquétipos - atos de apoderamento de coisas (vindicatio) e atos de apoderamento de pessoas (manus iniectio) - derivaram todas as ações (ações reais e ações pessoais) que a eles podiam ser reconduzidos. Em uma extensão do significado, ius também se chamou o lugar onde deveria reclamar-se um ius (uma actio): o tribunal do pretor e daí, uma estreita relação entre ius e imperium - a evolução constitucional rotre Auctoritas e Potestas Não se sabe concretamente a origem da palavra ius, não havendo acordo entre filólogos e juristas quanto à sua (ordengr preceitur) e, dí ius é o que é ordenado ou preceituado; b) ius deriva do ŝnscrito yum yug yung que sionifica ligação, liame. Por conseguinte, ius seria o estabelecido pelos julgadores (juízes) de um tribunal e reflete o pensar da comunidade (populus), já que esta declara o iustum e reprova o iniustum (o anormal): c) ius também pode ter origem no primitivo sânscrito yaus (puro, bom, santo), correspondendo à forma latina arcaica yous ou iuos: algo procedente da divindade. A partir deste provável significado primitivo, ius seria também derivado da forma antiquíssima de Júpiter (Ioues, Iovis), tendo um conteúdo ou sentido religioso que jamais se perdeu por completo, principalmente nos compostos, iurare (jurar) e iusiurandum (juramento). Por isso, ius tem uma relação de procedência com as divindades, sendo o que é "dito", pronunciado em um juramento. Quantò à noc̃o real de ius, a expressão pode ser tomada em pelo menos, 26 acepcões. Contudo, as principais são: a) ius é tudo aquilo que tem especiais atinências com o iustum (o justo, o exato, o devido); b) em um sentido normativo, ius é $O$ ordenamento jurídico (Ulpiano, D.1.1.1.3: Ius naturale est, quod natura omnia animalia docuit $\mathrm{O}$ direito natural é o que a natureza ensinou a todos os animais; Ulpiano, D.1.1.1.4: Ius gentium est, quo gentes humanae utuntur/ $O$ direito das gentes é aquele do qual os povos humanos se utilizam.); $\mathrm{c}$ ) em sentido subjetivo, ius é potestas: situação jurídica (status) poder ou faculdade moral que alguém tem sobre outrem ou sobre uma coisa: potestas: situação jurídica (status), poder ou faculdade moral que alguém tem sobre outrem ou sobre uma coisa, primordial para os romanos; e) ius também significa o lugar onde se administra a justiça (XII Tábuas, I,1: Sin ius primordial para os romanos; e) ius também significa o lugar onde se administra a justiça (Xif Tabuas, I, 1 Sin ius
vocATquEAT/ Se alguém é chamado a Juízo, compareça e Paulo, D, 1 ,11: ...Alia significatione ius dicitur locus in quo ius redditur, appellatione collata ab eo quod fit in eo ubi fit Por uma outra significação se diz direito o lugar em que o direito é distribuído, denominação conferida por aquilo que se faz em lugar de onde se faz). Já a palavra direito (derecho, recht, droit, diritto, etc.) - directum - pertence à linguagem vulgar tardo-romana $\mathrm{e}$ reflete a idéia moral que a conduta justa é aquela que segue o caminho reto. Todavia, Sebastião Cruz assinala que a tradição jurídica romana conhecia o termo rectum, que significava uma parte do símbolo da justiça: o fiel da balança. Assim, há ius porque a lustitia (a deusa) o diz e ela só o faz quando o fiel está aprumadíssimo (examen de-rectum) e, portanto, os dois pratos iguais. Da mesma forma, segundo o autor, há derectum "porque o fiel da balança está totalmente aprumado, e o examen está (rectum ou) de-rectum, quando os dois pratos estão precisamente iguais, i.é., exactamente no mesmo nível". Além de Sebastião Cruz, (nota 1), pp. 7 a 32, ver D’Ors, (nota 1), pp. 43/44, e CLAVERO, Bartolomé. Instituicion Historica del Derecho. Madrid: Marcial Pons, 1992, pp. 19/20. Textos do Digesto in: GARCíA DEL CORRAL, D. Ildenfonso. Cuerpo del Derecho Civil Romano. Ed. Facsímil. Valladolid: Lex Nova, 1989. Texto de Gaio, conforme manuscrito veronês, in: Gaius. Institutes. Paris: Les Belles Lettres, 1979.

${ }^{3}$ Cf. D'ORS, (nota 1), p. 47 e SEBASTIÃO CRUZ, (nota 1), p. 55. 
mana determinou, em grande parte, os traços gerais do desenvolvimento do direito privado porque este se apresenta como uma expressão do poder político de Roma, uma criação de seu gênio político. Com a evolução, o ius passa ser, mais genericamente, a "ordem judicial socialmente admitida, formulada pelos que sabem do justo: pelos iuris prudentes".

O direito dos romanos da época republicana se formou e progrediu por meio da tensão entre a autoridade (auctoritas) ${ }^{5}$ dos jurisprudentes e o poder (imperium e potestas) do povo, consubstanciado nas leges das as sembléias e nos editos dos pretores. Isto foi assim porque o ius, para ser eficiente, necessita da autoridade, do prestígio dos juristas. Estes, além da ciência, precisam do prestígio socia proveniente de sua linhagem, do caráter político de suas respostas ou da força da burocracia imperial para que suas doutrinas triunfem. ${ }^{6}$

\section{A - A lex publica e a Auctoritas dos juristas}

O uso de promulgações estatais sempre foi parcimonioso e objeto de uma severa moderação, já que a produção do direito não se dava só por meio da emanação de normas gerais e abstratas, mas, principalmente, a partir da solução de casos concretos. A lei pública, nas fontes romanas é o que relaciona, de forma que a lei religiosa é aquilo que relaciona o homem aos deuses, e lei humana é o que relaciona os homens a seus semelhantes. Fruto da vontade popular organicamente manifestada, a lex publica pode ser vista como um acordo entre o magistrado rogante e o povo que vota a rogatio exigindo o concurso de duas vontades ${ }^{7}$

$\mathrm{Na}$ época republicana, recorria-se à lex (ordem geral abstrata e estatal, expressão da potestas e do imperium do povo), para a estipulação de tratados internacionais, para o ordenamento de províncias e municípios, para

4 D'ORS, (nota 1), p. 43.

${ }^{5}$ Auctoritas (autoridade) é o prestígio social de uma pessoa ou instituição e "princípio da autoridade", o conceito de que a autoridade deve ser valorizada na vida social e na vida jurídica. Este princípio exerceu função decisiva na regulação da família e do Estado (a união das famílias) romanos. Com efeito, a vida familiar romana se baseava em relações autoritárias de supremacia do pater. A soberania doméstica implicava domínio absoluto sobre pessoas e bens: ao lado dos escravos e dos estrangeiros, que no campo do direito privado estavam submetidos ao domínio ou podiam cair nele, encontravam-se todas as pessoas submetidas à potestas, que no direito privado estão em propriedade alheia, mas do ponto de vista da civitas (Estado), se denominam liberi, em contraposição aos escravos. Assim, fora da relação mesma de supremacia, não podiam existir relaçōes de direito privado entre o titular do poder e seus submetidos. Como a vida do Estado também estava organizada segundo o princípio da autoridade, todo o direito das magistraturas estava construído com a finalidade de valorizá-la e conservá-la. Nas mãos dos titulares do imperium (supremacia do Estado que se personifica no magistrado), como também dos censores, ediles e tribunos, residia a pública disciplina, como nas mãos do paterfamilias a disciplina doméstica. O Senado era instituição política concreta que traduzia a autoridade, uma vez que os senadores - patres da República - dela estavam investidos porque reencarnavam os ancestrais, cuja autoridade no corpo político derivava de terem fundado a cidade. Através dos senadores, os fundadores se faziam presentes, "e, com eles, o espírito da fundação, o começo, o principium e a norma daquelas res gestae, as quais, a partir de então, formaram o povo de Roma", como afirma Hannah Arendt. A espinha dorsal da história de Roma foi, então, a coincidência da autoridade, da tradição e da religião, que emergiram simultaneamente do ato de fundação. Para estas considerações, ver, principalmente: SCHULZ, (nota 1), pp.187 a 209; MOMMSEN, Teodor. Compendio del Derecho Publico Romano. Buenos Aires: Editorial Impulso, 1942, pps. 11 a 19; ARANGIO-RUIZ, (nota 1), pp. $38 / 39$ e ARENDT, Hannah. Da Revolução. Brasília: Unb, 1990, p.161.

${ }^{6} \mathrm{Cf}$. CRUZ, (nota 1), p. 58

Cf. BARBAS HOMEM, Pedro. Jus e Lex. In: Estudos de Direito Romano. Lisboa: AAFDL, 1989, p. 242. Ver, também: Gaio, I. 3: "La loi est ce que peuple prescrit et établli"; Papiano, D.I.3: "Lei é preceito comum, decreto de homens prudentes, correção dos delitos que por vontade ou ignorância se cometeu, e pacto comum da república"; Modestino, D.I.3.7: "a virtude da lei é esta: mandar, proibir, permitir, castigar".

Revista da Faculdade de Direito da UFRGS, v. 21, Março/2002 a resolução de questões particulares de direito constitucional e administrativo e para estabelecer normas de organização ou de caráter econômico e social, como a lex Aebutia (introduziu o processo formulário) ou as leis agrárias. $\mathrm{O}$ direito privado e penal foi muito pouco afetado pelas leis, sendo que no direito privado esta só intervinha para evitar inconvenientes sociais ou para fixar normas tão precisas que não poderiam surgir de outro modo, como a composição de danos da lex Aquilia ou o estabelecimento de uma quota isenta de legados nas heranças, caso da lex Falcidia.

$\mathrm{Na}$ República, a lex votada pelo comício necessitava da aprovação, da ratificação do Senado, ou melhor dizendo, de um reforço - a auctoritas patrum. ${ }^{9}$ Dado que o Senado não era um órgão legiferante, mas consultivo, este ato não era propriamente um controle de constitucionalidade sobre a deliberação comicial e sim uma apreciação de mérito sobre ela, de modo que a aprovação do ato remetia-se ao prudente arbítrio do Senado. Com as leis Publilia e Menia, a patrum auctoritas se transformou num parecer não vinculativo. Daí que as deliberações comiciais eram atos complexos, porque requeriam a colaboração de três órgãos constitucionais (magistratura, povo, Senado -

rogatio, iussus, auctoritas): o povo manifestava sua vontade de maneira juridicamente vinculantiva, a magistratura constituía o centro motor da vida citadina e personificava em si a essência da res publica e o Senado era a consciência que guiava e dirigia, com sua soma de sabedoria e tradição, a vontade do povo e a iniciativa da magistratura.

Senatusconsultus era uma manifestação diversa, pois representava uma antecipação do Senado, um consilium: uma coisa era a aprovação seguida do voto popular e condição indispensável de sua eficácia, e outra bem diferente era a formulação de um parecer que precedia a execução de um provimento do magistrado. De qualquer modo, os senatusconsultus obtiveram valor normativo no fim da idade republicana, tanto no que dizia respeito ao direito público quanto ao direito privado, mas suas intervenções no direito privado foram ocasionais. ${ }^{10}$ Por conseguinte, os territórios centrais do direito privado - contratos, propriedade, servidões, casamento, filiação e herança - permaneceram quase isentos de leis ou ordens estatais gerais, sendo o objeto da arte dos juristas e da recepção pelo comportamento.

Em tempos antigos, os juristas eram sacerdotes, os sábios da cidade, pois em suas

${ }^{8}$ Além das citadas, são da época republicana: lex Poetelia de nexis (326 ou 313 a.c.), suprimindo a morte e escravidão por dívidas; lex Cincia (204 a .c.), sobre doações; lex Plaetoria (cerca de 200 a.c.), sobre validade dos negócios jurídicos conclúdos por menores; lex Atilia (anterior a 186 a.c.) sobre tutelas; lex Voconia e lex Furia testamentaria (a primeira do ano 169 a. c.), que estabelecem limitações aos direitos sucessórios das mulheres e outras limitaç̃es para aquisição por testamento. Possivelmente datam da segunda metade do século III a.c. as leis Publilia, Appuleia, Furia y Cicereia de sponsu, que tratam de fianças. Conforme SCHULZ (nota 1), pp.27 a 38: KUNKEL, Wolfgang. Derecho Romano Privado. Madrid: Labor, 1937, pp. 8/9 e ROTONDI, Giovanni Leges publicae populi romani. Estrato dalla Enciclopedia Giuridica Italiana. Hildesheim, Zurich, New York: Leges publicae populi
Olms, 1990, passim.

9 Ver, para isso: BISCARDI, Antonio. Auctoritas Patrum. Problemi di Storia del Diritto Pubblico Romano. Napoli: Jovene Editore, 1987, passim; SCHULZ, (nota 1), pp. 32/33; GALLO, Fillipo. L'Officium del Pretore nella Produzione e Applicazione del Diritto. Torino: Giappichelli Editore, 1997, pp. 42/43; KUNKEL, (nota 1), pp. 17/18.

${ }^{10}$ Exemplos são o SC Macedonianum - proibição de empréstimos a filiifamilias; SC Velleianum - proibição para as mulheres de intercedere; SC Claudianum - proibição de relaçôes sexuais entre mulheres livres e escravos alheios; SC Trebelianum e Pegasianum - sobre fideicomissos universais; SC Tertulianum e Orfitianum sucessão intestada de mães e filhos. 

coletividade, como o controle social do tempo mãos repousavam os conhecimentos civis da (calendários, plenilúnios, dies fasti, etc.), ${ }^{11} \mathrm{e}$ aqueles com os quais era possível regular a pronúncia do ius e as relações entre os grupos familiares, baseando-se na memória dos mores. Através do responsum, respondiam às perguntas dos patres que desejavam saber o que era $o$ ius em casos particulares, qual a conduta e o gestual para atingir determinados fins, seja nas relações interfamiliares, seja nas relações com o divino.

$\mathrm{Na}$ época republicana, o jurista passou a ser o "nobre-sábio", pois dar responsa assumiu um caráter aristocrático, ligado à hegemonia da nobilitas patrício-plebéia, saída das lutas sociais dos séculos V e IV a.c. Nesta mudança, contudo, permaneceu firme a idéia de que a interpretação do direito continuava a ser uma tarefa "de quem exerce poder na cidade". ${ }^{12}$ Os responsa constituíam o direito vivo da civitas, mas não estabeleciam regras gerais, como o fazia a lei pública.

No Principado, desaparecida a antiga legislação, a formulação de regras gerais passou a ser expressão da autoridade do Senado

(senatusconsultus) e do Príncipe (constitutiones), ${ }^{13}$ mas, no plano formal, estes poderes de criar direito, principalmente o do Príncipe, podiam ser reconduzidos à soberania popular, através da ficção da lex de imperio, de modo que o imperador, investido do iussu populi e exercendo este poder vice populi, não detinha um poder normativo absoluto, mas discricionário. Formalmente, aliás, Populus e Senado continuavam os titulares da soberania. O Príncipe, então, exercia uma função (poder-dever) em nome e no interesse do povo, inspirando-se no critério do bonum et aequum, tal como o pretor republicano. ${ }^{14}$

A seu lado, estavam os jurisconsultos disputando o monopólio da produção jurídica, pois nesta época ocorreu a "revolução científica" em que os juristas aprofundaram sua autonomia e a vocação técnico-especialista de sua doutrina e inauguraram um diálogo ininterrupto com o poder imperial a ponto de receberem a garantia substancial de um respeito pela jurisprudência na hierarquia das fontes da produção do direito. Associando-se ao poder político, em uma estreita colaboração poder a poder, os juristas, ao deterem o ius respondendi, aca-

${ }^{11}$ Cf. SCHIAVONE, Aldo. O Jurista. In: O Homem Romano. GIARDINA, Andrea (org.). Lisboa: Editorial cultural ao organizar a vida publica e cotidiana. In História e Memória(Calendário). $3^{*}$ ed. Campinas: Editora

12 SCHIAVONE, (nota 11), p. 79.

${ }^{13}$ Constitutiones eram as disposições imperiais, decorrentes do exercício normal das funções de magistratura pelo Imperador - primeiro cidadão, que se propunha a dirigir a vida política mais por sua autoridade pessoal (auctoritas) que por seus poderes (potestas) - e, por isso mesmo, alcançaram na prática jurídica e na consciência do povo o mesmo valor das leis. Os poderes do Príncipe correspondiam à sua função de magistrado, de modo que as Constitutiones, com força de lei, eram decorrentes de seu poder jurisdicional, ou de magistrado que administra a justiça. Seus editos tinham a mesma forma dos editos dos demais magistrados; os decreta eram atos de jurisdição (decisões de seu consilium) e os rescriptos, consultas sobre casos litigiosos A finalidade da legislação imperial dos primeiros anos do Principado foi o desenvolvimento do direito. Daí muitas leis importantes do Imperador contaram com o assentimento do comício, como: lex Iulia de collegiis, de 21 a.c. (sociedades); leges Iulia de maritandis ordinis e de adulteriis coercendis, ambas de 18 a.c. (dignificação do casamento elevação da moralidade); lex Papia Poppae, de 9 a . c; leges Iulia iudiciorum publicorum et privatorum, de 17 a.c. (organização judicial); lex Fufia Caninia e lex Aelia Sentia, de 2 a.c. e 4 d.c., respectivamente (sobre limitação à manumissão de escravos); leges Iulia de vi publica et privata, de 17 a . c. (publicização do direito

${ }^{14} \mathrm{Cf}$. GALLO, (nota 9), pp.40 a 45.

Revista da Faculdade de Direito da UFRGS, v. 21, Março/2002 Presença, 1992, p. 77. Sobre o calendário, Jaccques Le Goff, afirma que este é sobretudo um objeto social da Unicamp, 1994, pp. 485 e ss. baram por consolidar um direito dentro dos parâmetros da utilidade e da certeza, até que, na época pós-clássica, a jurisprudência sofreu a última alteração de funções e posicionamento: a nova configuração do governo e do poder anularam a sua autonomia. Além disso, todas as demais fontes do direito desapareceram, de sorte que a legislação do imperador (que acumula, em sua pessoa, toda a autoridade e poder) passou a ser a única fonte criadora do ius.. $\mathrm{O}$ direito acabou-se por identificar-se com a lei. $^{15}$

Os juristas com suas técnicas e sua atuação como membros dos consilium dos magistrados jurisdicionais, desenvolveram formulários para o processo e para os negócios jurídicos dos privados (cavere), auxiliando magistrados e partes, mas seu trabalho principal residia nos responsa, nos quais o prudente reconhecia o direito em cada caso e declarava ditames sobre o ius: se havia ou não actio, a interpretação da lei, de uma fórmula ou de um testamento. A recepção moribus, seja pelo comportamento, seja pela interpretação dos prudentes, operava sobre elementos já existentes - $o$ ius era revelado, declarado. Ao jurista cabia reconhecer a existência de normas jurídicas e sua tarefa era indicar ao magistrado a solução adequada ao caso concreto com base nos costumes, nas leis, no edito e até mesmo na eqüidade e boa-fé. Com isso, no auge da Jurisprudência Clássica, foram desenvolvidos modelos de uma racionalidade quase sem conceitos e abstrações, mas voltada para um realismo empírico e para o cálculo distributivo. ${ }^{16}$
A força de cada responsa residia fundamentalmente no prestígio de seu autor (auctoritas) e no fato de os juristas pertencerem à nobilitas, de modo que a interpretação dos prudentes só foi criativa de direito quando revestida do imperium do magistrado ou do Príncipe. O valor destas respostas só se tornou unívoco com Adriano, por meio do recurso à ficção de uma communis opinio que guiava a jurisprudência oficial, concedida no âmbito do ius respondendi. Artífices não conscientes de um direito "racional" e "formal", pensando pela primeira vez em formas abstratas, os juristas se utilizaram do método dialético dos gregos para desenvolver a prática jurídica ou uma "arte politica", axiologicamente orientada, porque cada estágio da produção juridica tem valores a fazer cumprir, a levar para a vida prática. Tanto é assim que, nos primeiros séculos do Império, os jurisconsultos acabaram por criar o método científico do direito, liberaram-se do formalismo excessivo e conseguiram chegar à noções gesaber civil, organizado segundo critérios muito próprios, figurando como "o verdadeiro logos romano", ${ }^{17}$ marcando, para sempre a história do Ocidente.

\section{B -O método da interpretatio iuris}

A jurisprudência romana foi a "arte de separar", ${ }^{18}$ isto é, de distinguir o direito do não direito, de delimitar o campo do direito e reduzir o ordenamento jurídico a um sistema autônomo. No entanto, como funcionalmente a ordem rais. O ius, desse modo, se constituiu como um

${ }^{15}$ F. SCHIAVONE, (nota 11), pp. 82 e BARBAS HOMEM, (nota 7), pp. 228/229.

${ }^{16} \mathrm{Cf}$. SEBASTIÃO CRUZ, (nota 1), p,.79.

${ }^{17}$ A epxressão é de SEBASTIÃO CRUZ (nota 1), p. 79.

${ }^{18}$ IHERING, apud SCHULZ, (nota 1), p. 39. 
jurídica está ligada à ordem social, juntamente com o direito está o ordenamento do costume da moral, o plano das obrigações extrajurídicas que no mundo romano tiveram tanta importância e que formam o conteúdo predominante da palavra officium. ${ }^{19}$

Desde a Lei das XII Tábuas, os romanos puseram em prática esta diferenciação entre direito e não direito, mas isto não se fez arbitrariamente, primeiro em face da necessidad de liberdade que exigiu parcimônia na criação e reconhecimento das normas, segundo, porque confiavam na riqueza e tenacidade dos vínculos extrajurídicos; por último, porque tiveram consciência dos limites do direito ao excluir certas matérias, como a posição da pessoa na família, o matrimônio (os juristas guardam silêncio sobre os usos nupciais romanos e só o que se sabe é que o matrimônio livre se fundava no consentimento e era isento de formas), o conteúdo típico dos contratos de compra e venda, de arrendamento, de sociedade e a estrutura típica dos documentos da prática.

Os vínculos jurídicos que derivam da pietas, da fides e da reverentia - officium - são apenas mencionados, e a relação genética do direito com o mundo extrajurídico ficava fundamentalmente excluída da exposição científica do jurista, bem como a exposição do direito do ponto de vista econômico..$^{20} \mathrm{O}$ resultado global deste "isolamento" é que a jurisprudência clássica foi preferencialmente ciência do direito privado em vigor na cidade de Roma e na Itália.

A maneira de se expressar dos juristas dá a impressão de um direito natural que tem uma validade menos geral do que a pretendida pela filosofia estóica, "um direito natural que fica enquadrado na legislação romana, fazendo firmes certos conceitos fundamentais e certas máximas axiomáticas fundamentais". ${ }^{21}$ Os juristas aspiravam a encontrar a regra que resultava da natureza das coisas, da natureza das relações que a vida cria. Assim, nas matérias em que a legislação teve pouca ou nenhuma influência, a jurisprudência não se limita a expor o direito positivo mas aspira à elaboração de um direito natural, ao extrair imediatamente das relações da vida, a ratio iuris.

A interpretatio prudentium se caracterizou por ser uma atividade orgânica e casuística do conjunto dos juristas, porque "as fontes do Direito não podem escrever-se de modo que compreendam todos os casos que de vez em quando ocorrem, senão que basta que contenha os que ordinariamente acontecem" (D.1.3.10). Saber casuístico, cada solução de um caso prático se dava no convencimento e na vontade de que, produzindo-se novamente o mesmo caso, devia ter lugar a mesma solução. Este método pode ser assim descrito: ponderase sobre a solução mais razoável do ponto de vista prático, em consideração às circunstâncias. Após, evocam-se os casos semelhantes, os casos opostos e utiliza-se, finalmente, do argumento ab absurdo, reiterando que outra solução não seria razoável ${ }^{22}$ Os critérios para encontrar-se a solução mais razoável têm como

${ }^{19}$ Dever, obrigação moral, o que se deve fazer por obrigação, sentimento de dever. O primeiro sentido foi de execução de uma tarefa, tarefa a executar. A hipótese é que deriva da forma op(i) - fici - om : opifex, sendo $o p$ a raiz indo-européia. É provável que a origem do vocabulo seja grega, tendo penetrado na linguagem do direito público para designar encargo, tarefas de um magistrado, os magistrados mesmos. Na linguagem filosófica, traduz "o dever" e está relacionada a ops, opis - o serviço feito. Cf. Sêneca, indica função de um órgão e, na linguagem da Igreja, o que é atestado sempre: o ofício divino. Cf. ERNOUT, A. E MELLLET, A. Dictionnaire Etymologique de la Langue Latine (Histoire des Mots). 4a. ed. Paris: Éditions Klincksieck, 1985,, verbete "officium", p. 459; SANTOS SARAIVA, FR. Novíssimo Dicionário Latino-Português. 10"

${ }^{20}$ SCHULZ, (nota 1), pp. 43/44.

${ }^{21}$ SCHULZ, (nota 1), p. 55.

${ }^{22}$ Cf. BARZOTTO, Luiz Fernando. Prudência e Jurisprudência - uma reflexão epistemológica sobre a jurisprudentia romana a partir de Aristóteles. Direito \& Justiça. Vol. 23. Porto Alegre: EDIPUCRS, 2001, p. 242; KASER, (nota 1), p. 108 ; HOMEM, (nota 7), p.225

Revista da Faculdade de Direito da UFRGS, v. 21, Março/2002 fundamento o justo eqüitativo e como fim específico a utilidade (D.1.3.25) e a benignidade (D.1.3.18). ${ }^{23}$

A interpretação estava orientada para exigências do presente, de modo que esta ponderação sobre a racionalidade tornava-se uma ponderação sobre o método, uma consideração crítica ao método. Daí a interpretatio acabava por ter uma função crítica de todo o direito. O juízo crítico era realizado com a conjugação de diferentes fatos normativos entre si e a sua harmonização com as exigências da justiça e utilidade presentes no caso concreto. Quando ponderava a decisão do problema individual, o jurista acabava por realizar sua liberdade crítica frente à fonte do ius.

O jurista, com sua interpretação, coordenava os vários modos de produção normativa e dava ao aplicador - o magistrado - uma diretiva clara de como proceder: o prudente não era um "criador", pois atuava assistindo e ajudando a norma no momento em que se manifestava. O sentido de uma responsa prudentium é exprimir o conteúdo de uma regra individual que a decisão do magistrado tornará obrigatória e, assim, seu valor estava ligado ao modo de produção do Direito em que a responsa se inspirava: lei, costume, edito, senatusconsulto, etc. $\mathrm{Na}$ medida em que por meio do labor dos juristas sobre os diversos fatos de produção normativa foram elaborados conceitos, figuras, regras e princípios comuns, a interpretatio não foi só método, mas também substância jurídica: jurisprudente é o criador da prática jurídica.

$O$ processo, segundo o qual se atingia a norma partia da intuição de cada prudente, através da qual se encontrava a decisão mediante a compreensão imediata que não necessita de ar-

gumentação racional. A eficácia prática da decisão sempre dependia, contudo, da persuasão que o prudente poderia obter com sua resposta. A motivação racional surgiu por causa da disputatio fori (D.1.2.2.5) - confronto entre os prudentes e os oradores preparados dialeticamente $-e$, a partir disso a jurisprudência deixou de operar internamente apenas através do recurso ao precedente doutrinal. $\mathrm{O}$ prudente sai do círculo de casuística (ligação a uma opinião consolidada; motivação utilizando uma regula iuris; utilização de uma construção jurisprudencial; motivação fundada em uma opinião controvertida ou singular) quando passa a apelar para outras fontes normativas que estão além de sua competência, como a lei, o costume e o edito. No entanto, regressa ao círculo casuístico através da ponderação tópica dos fatos normativos e da sua conciliação com os moldes racionais internos da interpretação obtidos pelas sucessivas abstrações de casos concretos, como a regula, a definitio, conceitos-guia como a bona fides, animus, etc. Este método (indutivo) permitia uma livre indagação sobre os motivos de justiça material presentes no caso, de modo que o jurista podia colecionar tais motivos em estreitos critérios materiais de decisão. Com isso, o discurso jurídico desprendeu-se do problema e concentrou-se na regra, do particular passou ao geral.

Q. Mucio e Servio foram os primeiros a formularem as regras conclusivas abstratas e as fórmulas abstratas, e é desta época que provém a maior parte das autênticas regras escolásticas (regulae veterum), ainda que elementares. Se nas obras de ensino dominava o método abstrato, nas grandes obras dos jurisconsultos - os comentários ao edito ou os libri iuris civilis de Sabino, em especial os

${ }^{23}$ Cf. HOMEM, (nota 7 ), pp. 225 a 230. Celso, D. I, 3, 18: As leis se devem interpretar no sentido mais benigno, no qual se conserve sua disposição"; Modestino, D.I, 3, 25: "Nenhuma razão de direito, nem a benignidade da eqüidade permite, que as coisas que se introduzem saudavelmente pela utilidade dos homens, sejam levadas à severidade com uma interpretação mais dura contra o bem-estar dos mesmos."

Revista da Faculdade de Direito da UFRGS, v. 21, Março/2002 
Digesta de Juliano, os libri ad Edictum e ad Sabinum de Pomponio, de Paulo e de Ulpiano ressalta o método casuístico, isto é, a exposição se esgota em uma série de casos iguais em que a regra de direito encontra sua expressão sem estar formulada abstratamente. Assim, os princípios resultavam da casuística exposta, mas não estavam enunciados. Por isso, de acordo com Schulz, ${ }^{24}$ o último título do Digesto, que contém as reguli iuris, é "um monumento da jurisprudência regular pós-clássica bizantina."

\section{C - O edito e as fórmulas processuais} se completou quando surgiu uma terceira fonte de produção do ius, ao lado da lei e da jurisprudência: o edito do pretor, lançando luz sobre o comum fundamento sobre o qual repousavam as duas primeiras - o consentimento popular. $O$ pretor, magistrado que possuía uma parcela do imperium da res publica - a iurisdictio -, se encontrava em uma situação de superar os limites da ordenação jurídica existente e, assim, passar ao campo da livre criação. ${ }^{25}$ âmbito do procedimento civil ordinário, a autoridade para decidir, no caso concreto, se era permitido a alguém deduzir sua demanda diante de um juiz. Função estatal, outorgava-se a um magistrado (ao pretor, urbano ou peregrino, governador de província, ediles curuis e questores). Advém da distinção entre iurisdictio e iudicatio que o pretor era uma espécie de árbitro, visto que não dirigia, como o juiz moderno, todo o processo até a sentença: sua missão era constituir um tribunal arbitral (ou indicar, juntamente com as partes, o juiz) e
A formulação do ius civile romano só

Iurisdictio (ius dicere) indicava, no

encontrar um procedimento adequado, que se revestia em uma fórmula. De seu arbítrio dependia a admissão da demanda, de modo que, se a negava, o tribunal não se constituía e o demandado ficava sem proteção judicial. As possibilidades que se ofereciam à jurisdição do magistrado só não degeneraram em arbítrio puro pelo seu apego à tradição e à ordem constituída, pois só criava novo direito quando o caso assim exigia. No mais, atinha-se às soluções do direito vigente.

O edito era o programa oficial dos magistrados e, nele, o magistrado se dirigia ao povo indicando as ações da lei que protegeria, as situações de fato a que daria tutela jurídica (proteção), as ações que ele não aceitari (denegação de ações), as ordens relativas à ordem e à paz públicas, decorrentes exclusivamente de seu imperium - os interditos - , além das medidas políticas e administrativas para a vida cotidiana. O edito, assim, era uma espécie de compêndio das normas jurídicas, e como era anual, a cada ano renovava-se e modificava-se a norma jurídica. A chamada parte velha (trasladada) era o que o novo pretor pretendia manter e a parte nova eram as mudanças e acréscimos. Por ser decorrente do imperium e potestas do magistrado, que, em última instância, se reportavam à soberania popular, o edito também pôde ser chamado de lex annua. Uma inovação afortunada de um pretor passa a ser repetida, a ser ius honorarium através do edito do pretor, $\mathrm{e}$ finalmente, é recebida pelo ius civile, como no caso dos contratos consensuais. $\mathrm{O}$ edito não era o código de procedimento civil do império, como assegurou Brinz,$^{26}$ porque ele não continha propriamente direito civil, nem o direito de ações: apenas esses ramos do direito se re-

24 Cf. SCHULZ, (nota 1), p. 73.

${ }^{25}$ Cf. KUNKEL, (nota 8), p. 11.

${ }^{26}$ Cf. LENEL, Otto. Essai de Reconstution de L'Édit Pérpétuel. T.I. Paris: Librairie Edouard Duchemin, 1975, p. 11 .

Revista da Faculdade de Direito da UFRGS, v. 21, Março/2002 lacionam ao officium dos pretores, tanto urbano quanto peregrino. Para Lenel, o edito continha quatro divisões principais com apêndices: a parte preliminar, tinha por objeto regular e assegurar a marcha do processo até a organização do iudicium, isto é, garantia e regulamentação do poder jurisdicional em si mesmo; a segunda divisão, que continha meios de direito decorrentes da lei, com vários subtítulos; a terceira, que apresentava os meios de direito decorrentes do imperium, também subdividida; por fim, a quarta parte que abordava a execução e os recursos. Além disso, o edito continha quatro apêndices: os interditos, as exceções, as estipulações pretorianas e um final contendo o edito dos edis. ${ }^{27}$

Conforme o edito contivesse prevenções do magistrado, proibições, mandatos ou fórmulas processuais, a tutela jurídica oferecida era diversa, de modo que pode ser assim resumida: em alguns casos, a referida tutela se limitava a dar efetividade ao direito pré existente (legal ou consuetudinário), estabelecendo uma fórmula para a ação; em outros casos, a fórmula e a precedida de uma declaração de proteção.

Com a expansão de Roma em função do comércio marítimo e da indústria, cresce a relação com os estrangeiros (peregrinos), e estes passam a ser protegidos por um pretor especial, o Pretor Peregrino. Sob o reinado de Adriano (130 d.c.), o edito foi reunido e organizado (Edito Perpétuo) e o meio principal para determinar a ordem das matérias são os fragmentos dos libri ad edictum praetoris et aedilium curulium de Ulpiano e os libri ad edictum provinciale de Gaio, inseridos no Digesto. ${ }^{28}$ Os magistrados jurisdicionais, entretanto, eram muitas ve- zes jovens sem experiência que haviam sido eleitos mais por motivos políticos e pessoais do que por suas capacidades técnicas (conhecimento do ius civile ou dos mores) e, por isso, contavam sempre com o auxílio dos verdadeiros peritos, os jurisconsultos, que acabaram por construir um novo direito com sua técnica, a jurisprudência.

\section{II - Formulação, Interpreta- ção e Aplicação do Direito Através do Officium do Pretor e da Árs dos Jurisconsultos}

O discurso científico do jurista romano tinha dupla face: a da regra e a do caso concreto, de modo que ele operava sucessivas abstrações do caso concreto até chegar ao domínio de previsão de uma norma. ${ }^{29}$ Na primeira fase, só a inventio dos juristas pôde superar os dados do direito posto através da invocação da eqüidade ou boa-fé, mas a própria invenção já se dá sob o signo da questão concreta. Isto é assim porque se um saber pode ser sapientia (conhecimento abstrato), prudentia (saber-agir) e ars (saber-fazer), para os jurisconsultos romanos, o direito era fundamentalmente prudentia e ars. ${ }^{30}$

\section{A - O ius é uma prudentia e uma ars}

Como saber jurídico, o direito é uma prudência e uma técnica secundária e subordinada (ars). Como ciência diz o que é justo e o que é injusto (sapientia) e como alcançar o justo e evitar o injusto (ars). Saber complexo, tende
${ }^{27}$ Cf. LENEL, (nota 26), pp. 32 a 54.

${ }^{28}$ Ver, para isso, LENEL, (nota 26), p. 1

${ }^{29}$ Cf. BARZOTTO, (nota 22), pp. 221 e ss, passim e SCHULZ, (nota 1), p. 55.

${ }^{30}$ Cf. SEBASTIÃO CRUZ, (nota 1), p. 283. 
para a ação, para o honestum e por isso, é prudentia (phronesis): o prudens é aquele que, pressupondo a verdade das coisas (sapiens), vê as coisas em seu aspecto valorativo, de utilidade para o homem e para a comunidade. Daí que a iurisprudentia é ciência dos valores, pois a sapientia recebe a luz de pressupostos e verdades fundamentais. ${ }^{31}$

Como técnica (ars), o direito é um saber realizável, é o "fazer do saber", ${ }^{32}$ de modo que nesta acepção, o acento é posto no aspecto produção, interpretação e aplicação, isto é, no aspecto dinâmico deste saber. ${ }^{33}$ Dado que o direito não existe na realidade natural, é, como a linguagem, criação humana dirigida à finalidades práticas: assegura na comunidade humana as condições de convivência (instituição ou ordem) e é continuamente modificado mediante a atividade interpretativa e aplicativa. Dessa atividade emergem técnicas e regras para sua correta produção, interpretação e aplicação.

$\mathrm{Na}$ definição de Celso - ius est ars boni et aequi -, contida no fragmento de Ulpiano (D.1.1 )o aspecto de ars como atividade com técnicas e regras dirigidas a uma finalidade ou complexo de finalidades fica ressaltado, porque, do contrário, o jurisconsulto teria usado a expressão sapientia ou prudentia e não ars. $O$ ius é, por conseguinte, obra do homem (artificialis) em contraposiçãoà natureza (naturalis), porque cria o novo. Assim, a considerar-se a experiência como uma integralidade, o ius é atividade criativa dos jurisconsultos (que têm auctoritas) mediante atos políticos (de imperium e potestas) do magistrados.

A visão do ius como ars compreende tudo o que é necessário aprender, saber ou fazer tem vista a produção, interpretação ou aplicação do direito e daí ser a interpretatio iuris um labor constitutivo-elucidativo. ${ }^{34} \mathrm{~A}$ arte que é o direito tem a finalidade de descobrir o honesto, o útil e o oportuno na convivência social, ou seja, destina-se a alcançar umas coisas e evita outras e, dessa forma, ficam ressaltados o aspecto científico e o aspecto técnico. Como ciência, o direito destina-se a saber o que é justo ou injusto e, como arte, trata de saber como se pode alcançar o justo e evitar o injusto: como obter para os indivíduos e para a comunidade máxima utilidade compatível com a convivência. Por isso, na esteira do ensinamento de Celso - que ressalta o aspecto substancial - o ius é arte voltada para a individualização e realização do bonum et aequum . ${ }^{35}$

O que, no entanto, é o bonum et aequum? Depreende-se do texto Celsino que aequum é igualdade (campo de ação) e justiça (fim último), de modo que o direito, pela atuação da igualdade, tende para a justiça. Esta igualdade é jurídica ou proporcional (a situações iguais correspondem tratamentos iguais; a situações desiguais, tratamentos desiguais) e deve ser o critério fundamental a inspirar todas as normas. Isso é confirmado pelo uso do termo iniquitas, pois a medida iníqua é a que supera o limite da tolerância à desigualdade. ${ }^{36}$ bonum exprime junto com o aequum o elemento distintivo da arte que é o ius e é o honestum (lícito), o útil, de modo que a arte é preparar, na produção, interpretação e aplicação, a solução

${ }^{31}$ Cf. SEBASTIÃO CRUZ, (nota 1), p. 283 e ss e BARZOTTO (nota 22), passim.

${ }^{32}$ SEBASTIÃO CRUZ, (nota 1), p. 283

${ }^{33}$ Ver GALLO, (nota 9), p. 226.

${ }^{34}$ Ver Celso, D.1.3.2.4: "É contrário ao direito julgar ou responder com base em uma pequena parte da lei, sem haver examinado atentamente toda a lei."

${ }^{35}$ Cf. GALLO, (nota 9), p.240.

${ }^{36}$ GALLO, (nota 9), p. 247

Revista da Faculdade de Direito da UFRGS, v. 21, Março/2002 boa, segundo os critérios de respeito à igualdade. Com isto, a arte dos jurisconsultos não é formalista, porque eles não faziam prevalecer a lógica da abstração.

Incluir o ius no gênero ars evoca o dado de que o direito constitui historicamente um produto humano. Com isso, põe-se em relevo a exigência do aprendizado e da aplicação das regras e técnicas de sua produção, mais ainda para sua interpretação e aplicação; sublinha-se também a responsabilidade dos homens para 0 estado do direito em relação ao seu momento produtivo e aplicativo. Se é arte, serve-se não só da razão, mas da memória, da intuição e do sentimento; em suma, da tradição. Sendo assim, o que distingue o ius do gênero ars é a nota diferencial "bonum et aequum", isto é, o seu objeto, de forma que o decisivo é a substância, a adequação ao objeto e à finalidade. ${ }^{37}$

Se a ciência prática (prudentia) e a técnica (ars) se complementam, a arte é o modo de aplicar e comunicar a ciência, é o aspecto prático da ciência e tem que pressupor o reconhecimento sem discussão (notitia) das verdades divinas e humanas, ${ }^{38}$ ou seja, o reconhecimento dos pressupostos da ordem teológia (res divinae) e filosófica (res humanae) que informam a vida de um povo. Por isso, a filosofia que os jurisconsultos se serviam era mais pragmática e moral do que especulativa.

Guiada por um senso prático e pela simplicidade dos juristas, a jurisprudência clássica expressou uma enérgica parcimônia na criação e utilização das instituições jurídicas, de modo que uma única instituição servia para fins muitos distintos, e relações sociais diferentes estavam sujeitas a um mesmo regime jurídico. As-

${ }^{37}$ Cf. GALLO, (nota 9), pp. 262 e ss.

${ }^{38}$ Cf. SEBASTIÃO CRUZ, (nota 1), pp. 285 e 286

${ }^{39} \mathrm{Cf}$. D'ORS, (nota 1), p.

${ }^{40}$ ERNOUT MEILLET, (nota 19), p. 233 e D'ORS, (nota 1), pp. 31/32 sim, por meio da obra minimalista dos jurisconsultos e dos comportamentos sociais, foi feita a extensão de figuras jurídicas existes a outros supostos de fato, criando-se, assim, por esta via, novas figuras negociais e institutos jurídicos.

\section{B - A extensão do ius civile aos estrangeiros através do officium do pretor}

Os romanos tiveram consciência da superioridade de seu ius civile: nele se encontram instituições consideradas de validez geral para todos os povos relacionados com Roma porque se fundavam, muito mais do que na forma, no princípio da fides, vocábulo da língua latina que indica, em sentido religioso, "fé", "confiança" e, na linguagem do direito, "lealdade à palavra dada". ${ }^{39}$

Idéia central do pensamento jurídico e político de Roma, fides é a virtude do mais poderoso, e daí a exclamação "pro deum fidem", que indica a proteção dos deuses. Esste significado foi conservado na linguagem da Igreja também no sentido de "credo". ${ }^{40} \mathrm{Na}$ linguagem do direito, a palavra ganhou extensão para significar "vínculo solene", "garantia dada", "boafé", "lealdade", "fidelidade à palavra dada" e "confiança". Dessa palavra derivaram outras compostas, como fideicomissum, fideipromissor, todas elas com um sentido residual de "confiança", "garantia". Assim, o que ressalta da expressão é o aspecto "fidelidade", sujeição à palavra dada, o sentir-se ligada às próprias declarações. A fides romana também era a firmeza de Roma em relação a seus aliados, daí foedus (aliança), fides tutoris, etc. Para os romanos, 
ser fiel era um princípio vital ${ }^{41}$ e era um dos aspectos da constantia (virtude central do homem).

Ao princípio da fides o direito romano deve certas características particulares, como o pronto reconhecimento dos negócios jurídicos não solenes, pois a fides chega lá onde a força vinculantiva da forma não alcança. $\mathrm{Na}$ época republicana, surgiram os contratos consensuais como a compra e venda, arrendamento, sociedade e mandato e também os contratos reais não solenes, tais como o mútuo, o depósito e o comodato, todos ações em boa-fé (bonae fidei iudicia). Também a existência de pactos pretorianos providos de ação se devem ao princípio da fides, como o constitutum, o receptum argentarii e $o$ arbitrii. Da mesma forma, a entrega não solene de res nec mancipi, o penhor, o início não solene do matrimônio (casamento livre) e o fideicomisso (admitido e aceito inter vivos) obrigavam o gravado à fidelidade, a manter sua palavra. Relativamente a este último, só na época de Augusto se transformou em uma obrigação jurídica (Institutas, II, 23).

Por obra dos jurisconsultos e dos pretores e dos comportamentos dos cidadãos, na época clássica, foi ampliado o círculo dos negócios não solenes, de forma que a mancipatio e a in iure cessio caíram em desuso e foram finalmente abolidas. No mesmo período, a estipulação transformou-se em um contrato - oral ou escrito - entre presentes, com a principal característica da fides: do contrato obrigatório válido nascia um vínculo rígido que não podia ser rompido. Por isso, adverte Schulz, ${ }^{42}$ o problema da eficácia vinculante da oferta nunca se pôs para os romanos, pois, embora conhecido o contrato entre ausentes, ele não era freqüente: para concluir um negócio, recorria- se aos escravos, libertos e amigos. Em face da força obrigatória dos contratos, decorrente da fides, o direito romano não conheceu o direito facultativo de resolver o contrato por descumprimento, à exceção do mandato.

$$
\text { As primeiras manifestações da bona }
$$
fides relativamente aos contratos válidos dizem respeito à cláusula formulária ex fide bona contida nos bonae fidei iudicia, que obrigavam o juiz a considerar as convenções acessórias, se as partes em um contrato de venda podiam pretender que se fizesse a contraprestação só no momento de sua prestação ou, ainda, se, no processo fundado na estipulação, a exceptio doli permitia levar em conta o pactum de non petendo carente de formas. Isso era assim porque os bonae fidei iudicium eram procedimentos ante o juiz segundo os quais se lhe ordenava que sentenciasse conforme os ditames da boa-fé. Para isso, se introduzia na intentio da fórmula uma cláusula especial, aberta, de modo que o juiz estava autorizado a levar em conta os usos e costumes do tráfego negocial. Em suma, o juiz deveria atuar conforme as exigências das boa-fé.

O significado originário do iudicium bonae fidei era o de que o juiz devia decidir conforme à boa-fé e não ex iure Quiritum. Assim, por exemplo, na época em que a fórmula venditi foi criada, o contrato não formal de compra e venda não estava ainda reconhecido pelo ius civile, de modo que a actio venditi só podia fundar-se na boa-fé e não no direito civil. $\mathrm{Na}$ época clássica, em que foi reconhecido pelo ius civile o contrato não formal de compra e venda, a significação da cláusula ex fide bona modificou para determinar a medida e o alcance da execução do contrato e não mais para constituir a base da ação, como no regime anterior.
${ }^{41}$ SCHULZ, (nota 1), p. 244.

${ }^{42}$ SCHULZ, (nota 1), p. 246

Revista da Faculdade de Direito da UFRGS, v. 21, Março/2002
O Edito Perpétuo contém uma secção em que estão listados os bonae fidei iudicia porém esta lista não é completa. No texto reconstituído por Lenel e no que está contido no fragmento 1 de Ulpiano, Título III, Livro XVI do Digesto, por exemplo, figura a ação de depósito, direta ou contrária, assim prevista pelo pretor: "Pelo que foi depositado, se não é por causa de tumulto, incêndio, ruína, naufrágio, darei ação contra o depositário pelo simples; mas se o depósito se deu por algumas destas causas acima compreendidas, darei ação em dobro contra o mesmo e contra seu herdeiro, pelo que se houver notícia que obrou em dolo mau o morto, pelo simples; se por dolo do herdeiro, pelo dobro". ${ }^{43}$

Também o edito continha l'actio fiduciae que funciovava como actio directa e como actio contraria. Relativamente à fórmula desta ação, sabe-se apenas que ela continha a cláusula característica "ut inter bonos bene agier oportet et sine fraudatione" e que com uma ligeira mudança era igualmente aplicável à fiducia cum amico contracta ${ }^{44}$ o mandato, cuja fórmula continha claramente as expressões dare facere oportet ex fide bona ${ }^{45}$ a sociedade, que admitia o herdeiro do associado como demandado, como transparece na fórmula comentada por Ulpiano, verbis: "in heredem... socii proponitur actio, ut bonam fidem praestet"; ${ }^{46}$ a compra e venda, a locação, e a ação estimatória.

Quanto a esta última, Lenel assevera que, neste caso, o pretor deu "um exemplo da maneira que se pode tratar, do ponto de vista do procedimento, dos contratos que não podem ser enquadrados em nenhum caso habitual; e é assaz natural que os jurisconsultos se tenham acostumado a considerar como um princípio geral o que esta ação propunha para um caso particular." 47

Gaio apresenta igualmente uma lista que pretende ser exaustiva, sendo duvidoso que o seja: "As ações em boa-fé são as seguintes: de compra e venda, locação e condução, gestão de negócios, mandato, depósito, fidúcia, sociedade, tutela, restituição do dote da mulher, comodato, penhor, divisão de herança e divisão de coisa comum." (4.62) ${ }^{48}$ Como se vê, nesta lista estão incluídas ações que, no Edito reconstituído, não figuram como bonae fidei iudicia em sentido estrito, como a ação de tutela ou a ação de restituição do dote da mulher.Em síntese, os juízos que não fossem bonae fidei iudicia não tinham esta denominação comum, já que em muitos deles se dava também a bona fides na mesma medida que nos bonae fidei iudicia propriamente ditos.

$\mathrm{O}$ juiz podia interpretar discricionariamente a cláusula ex fide bona, mas, no geral, ficava adstrito à tradição, isto é, adotava a doutrina jurídica estabelecida. Na doutrina das fontes do direito, o princípio da fides implicava duas regras: a) o magistrado estava vinculado a seu ${ }^{43}$ Cf. LENEL, (nota 26), pp. 1 a 5 e Ulpiano, D. 16. 3.1.1.: "Praetor ait: QUOD NEQUE TUMULTUS, NEQUE
INCENDII, NEQUE RUINAE, NEQUE NAUFRAGIU CAUSA DEPOSITUM SIT, IN SIMPLUM, EX EARUM AUTEM RERUM, QUAE SUPRA COMPRAEHENSAE SUNT, IN IPSUM IN DUPLUM, IN HEREDEM EIUS, QUOD DOLO MALO EIUS FACTUM ESSE DICETUR, QUI MORTUS SIT, IN SIMPLUM, QUOD IPSUS, IN DUPLUM IUDICIUM DABO." (Nota 1), T.I, p. 831.

${ }^{44}$ Lenel comenta que provalvelmente o termo pignori, que se encontra no Digesto $(13,6)$ foi interpolado. (Nota 26 ), pp. $7 / 8$.

${ }^{45}$ Cf. LENEL, (nota 26), p. 10.

${ }^{46}$ Cf. LENEL, (nota 26), pp. 12 e ss.

${ }^{47}$ LENEL, (nota 26), pp. 16/17.

${ }^{48}$ GAIO, (nota 1), p. 157. 
edito (o que havia escrito, havia escrito) e b) as normas jurídicas não tinham eficácia retroativa. Daí que a violação da fides pelos magistrados poderia ter por sanção a intercessio; no segundo caso, só excepcionalmente as normas jurídicas - procedessem elas do edito, das leis ou das constituições - retroagiam, como, por exemplo, em matéria procedimental no âmbito penal..$^{49}$

A expressão bona fides também assumia o significado de honestidade, porque, na mentalidade romana, fé e honestidade estavam muito próximas. Responder de boa-fé significa não só manter a palavra como também "ter um comportamento que responda ao costume de gente honrada, cumprir o próprio comportamento em relação aos usos comerciais." 50

No plano extrajurídico, também a fides atuou na vida romana, visto que as relações duradouras de fidelidade eram numerosas, como por exemplo a relação entre patrono e liberto, que continha as obrigações de reverentia obsequium, ou a relação de uma comunidade inteira com um patrono. Nestes casos, a relação de fidelidade era trasmissível e obrigava à ajuda recíproca. O tratado de hospitalidade hospitium - que podia ser constituído entre indivíduos ou entre comunidades também era uma manifestação da fides romana. A finalidade principal deste tratado era o cuidado do hóspede, mas o mesmo poderia estender-se à gestão de negócios ou à tutela judicial. Conseqüentemente, por esta via, alguns dos direitos exclusivos dos cidadãos eram alcançados aos estrangeiros.

As relações de amizade privada também criavam relações duradouras de fidelidade e se projetavam na vida jurídica; basta ver a importância de negócios como o mandato e a gestão

de negócios, que figuram entre as instituições jurídicas mais importantes. A importância das relações de fidelidade também explica o fato das garantias pessoais prevalecerem sobre as garantias reais, bem como a freqüência com o direito romano recorria às cauções. Além disso, sobressai a apresentação obrigatória de garantias pessoais nos contratos com os censores e a instituição do consilium, que não pode ser concebível "sem um círculo de amigos e patronos a quem se pode confiar importantes encargos de negócios, que esperam ser chamados para isto". ${ }^{51}$ Por estas razões, noção de fides é uma idéia fundante de todo o ordenamento jurídico romano, pois só através das relações de fidelidade é que muitas regras se tornam compreensíveis.

\section{C-Ius Gentium e Ius Naturale}

$O$ equilíbrio entre exigências sociais e estrutura jurídica começou a romper-se no curso do terceiro século a.c., com a expansão de Roma, que, de uma cidade pastoril e guerreira, se transformou em uma potência mediterrânea. Afirmaram-se, ao lado do latifúndio, as atividades comerciais e financeiras, a substituição do trabalho servil pelo livre, o luxo, a circulação da riqueza e a conseqüente mudança dos costumes.

As novas necessidades e os novos valores sociais resultantes do desenvolvimento do comércio marítimo e terrestre e das novas ou mais intensas atividades não agrícolas (mineradoras, artesanais, industriais ou financeiras) não implicaram, contudo, nenhuma reforma radical no ius civile. Para satisfazer essas necessidades e respeitar esses valores, foram criados novos ramos, novos conjuntos, isto é, regras e princípios e estes foram o ius gentium e o ius honorarium ou praetorium. Por isso, os romanos, em 242 a.c., introduziram, ao lado do pretor urbano, o pretor peregrino, também investido de jurisdição pela assembléia popular e cuja função era ius dicere nas controvérsias entre peregrinos ou entre romanos e peregri$\operatorname{nos}($ D. 1.2.2.28).

Enquanto em Roma vigorava o princípio da personalidade do direito, o ius civile (direito romano substancial e processual) não era aplicável, de pronto, às relações inter peregrinos. Em princípio, o não-romano carecia em Roma de todo direito, se não possuísse o hospitium - direito de hospitalidade decorrente da fides -. Dado que as relações de hospitalidade podiam estabelecer-se particularmente entre estrangeiros e cidadãos ou entre município e município, foi esta segunda forma de hospitium a principal base do progresso das relações internacionais de Roma.

Mediante um tratado de comércio ou de amizade, podiam ser reconhecidas aos cidadãos de países estrangeiros a capacidade de realizar negócios jurídicos e a defesa de seus direitos pelos tribunais romanos. Assim, em alguns casos, o estrangeiro era equiparado ao cidadão romano na esfera patrimonial, porque lhe era concedido o ius commercii e porque se lhe permitia o consórcio matrimonial (ius conubii, conubium). Nestas circunstâncias especialíssimas, o pretor peregrino utilizava o sistema da legis actiones para resolver a controvérsia mediante $\mathrm{o}$ expediente da fictio civitatis, principalmente no âmbito dos delitos privados. O testemunho de Gaio (4.37), nesse sentido, é elucidativo:

"Também a cidadania romana já se atribui ficticiamente ao peregrino, quando for autor ou réu numa ação instituída por nossas leis, contanto seja justo estendê-la mesmo ao pere-

${ }^{52}$ Ticio seja juiz. Uma vez que AA comprou o escravo em questão de NN (a coisa de que se trata); verificado tudo o que NN teve que dar ou fazer, segundo a boa-fé, no confronto com AA, o juiz condena NN em favor de AA; se não resulta, absolva. Cf. GALLO, (nota 9), pp. 31 e ss.

Revista da Faculdade de Direito da UFRGS, v. 21, Março/2002 grino; por exemplo, quando for autor ou réu numa ação de furto. Pois, sendo o réu peregriSE PARECER QUE, POR OBRA OU CONSELHO DE DION, FILHO DE HERMEU, LÚCIO TÍCIO FOFREU UM FURTO DE UMA TAÇA DE OURO; E VISTO QUE, EM VIRTUDE DE TAL ATO, DION SERIA CONDENADO POR FURTO, SEFOSSE CIDADÃO ROMANO, etc. Atribui-se também ficticiamente a cidadania romana ao peregrino que age por furto. Igualmente, se um peregrino for autor ou réu em uma ação de dano injusto, fundada na Lei Aquília, dá-se ação fingindo ser ele cidadão romano."

Tal equiparação, contudo, não se estendeu a todos os estrangeiros e, assim, o comércio jurídico com os não-privilegiados era objeto de uma regulamentação especial por tratados ou se regia por normas consuetudinárias formadas na prática do comércio internacional e da tutela dos estrangeiros. A via escolhida pelo pretor peregrino, neste segundo caso, era o sistema per formulas, e, nestas circunstâncias, o meio indicado estava em estreita correlação com a situação jurídica do ato e com a finalidade própria da jurisdição. No sistema das legis actiones, a fase in iure do procedimento era rigorosamente disciplinada, mas, nas causas entre estrangeiros, persistindo o sistema dual, a modalidade do procedimento in iure teve que são legislativa, era necessário um acordo dos litigantes no qual o iudicium dare da parte do magistrado era acompanhado do iudicium dictare e accipere das partes. O exemplo é a fórmula da actio ex empto, na qual se individua o nome do juiz, a indicação do negócio jurídico deduzido em juízo, a limitação da controvérsia, a pretensão alegada pelo autor e a atribuição ao juiz do poder de condenar ou absolver a controvérsia. ${ }^{52}$ no, a fórmula é a seguinte: FULANO, SE JUIZ. ser inventada, de modo que, na falta de previ- 
Este sistema de extensão da tutela processual aos estrangeiros desenvolveu-se rapidamente graças aos juristas que acompanhavam e sustentavam a obra dos magistrados. O juristas criavam para os casos mais frequientes fórmulas típicas, procedentes de figuras negociais já conhecidas, como a emptio, a venditio, a locatio, a societas, etc e elas valiam porque o pretor introduzia no edito uma clásula de pactis conventis segundo a qual prometia dar a adequada tutela a todos os pactos, tanto inter cives quanto inter peregrinos.

As figuras negociais criadas na jurisdição entre estrangeiros acabaram por se chama ius gentium e, inicialmente, esta denominação não indicava a abstração conceitual elaborada sucessivamente. Daí o primeiro significado de ius gentium ser concreto, prático: eram do ius gentium as figuras negociais praticadas, segundo o direito romano, entre romanos ou entre romanos e peregrinos. O ius gentium, por essa razão, não representava uma entidade contraposta ao ius civile ou dele separada. Entre eles havia diferenças, mas o primeiro era parte do segundo, isto é, o ius gentium era precisamente aquela parte do ius civile que se aplicava também inter peregrinos. ${ }^{53}$

O ius gentium, então, em sua essência, procedia do mesmo direito romano e não era distinto do vigente para os cidadãos romanos; deste se diferenciava, em termos gerais, porque não era tão formalista como o que vigorava para os cidadãos. Alguns institutos como a mancipatio e a in iure cessio não foram estendidos aos estrangeiros, e isso é compreensível porque nas fórmulas destes negócios, figurava a expressão ius Quiritum, denotando serem os mesmos privativos dos cidadãos romanos. A stipulatio, ao contrário, foi amplamente praticada entre os peregrinos, com uma pequena

variação na fórmula: em vez de empregar o verbo spondere, empregavam-se outros verbos, como promittis? promitto; dabis? dabo, etc. O reconhecimento da stipulatio em forma diversa daquela expressa no verbo spondere foi também obra da recepção moribus, isto é, do comportamento dos cidadãos. Por esta via, a estipulação e a fiança foram adaptadas para o comércio com estrangeiros mediante a substituição de fórmulas usadas entre cidadãos por outras que aqueles podiam validamente empregar. ${ }^{54} \mathrm{Em}$ suma, através da obra criativa de pretores e de jurisconsultos e do comportamento dos cidadãos, sugiram muitas figuras negociais como empréstimo simples, livre de formalidades, em lugar do empréstimo solene per aes et libram, ou, ainda, a simples troca de mercadoria e preço, em vez da venda mancipatória, e o penhor manual (pignus) no lugar da transmissão formal da coisa para garantia do credor (fiducia cum creditore).

O ius gentium, assim constituído, foi o resultado da confluência de elementos de diversas origens. Em parte era direito comum aos povos antigos do Mediterrâneo e do vizinho Oriente, como, por exemplo, o que reconhecia como fontes de escravidão o aprisionamento na guerra e o nascido de mãe escrava, ou aquele que, à guisa de direito internacional, regulava alguns aspectos das relações entre comunidades organizadas (regna, natione, civitates). Provinha também, em grande medida, dos usos do comércio marítimo e terrestre entre romanos e estrangeiros, usos conformes a critérios ético-sociais como os da fides ou da fides bona. Contribuíram também institutos romanos tornados acessíveis aos estrangeiros (como é principalmente o caso da stipulatio). Por fim, alguns institutos jurídicos estrangeiros foram recepcionados, como é principalmen-

${ }^{53}$ Cf. GALLO, (nota 9), p. 33

${ }^{54}$ Cf. GALLO, (nota 9), p. 34 e KUNKEL, (nota 8), p. 83.

Revista da Faculdade de Direito da UFRGS, v. 21, Março/2002 te o caso do foenus nauticum ou pecunia traiecticia (empréstimos a navegadores-empresários, com a assunção dos riscos da navegação mediante a compensação de juros adequados). Graças principalmente aos juristas, tais elementos se fundiram na noção unitária do ius gentium como direito autenticamente romano, tendo como denominador comum a aplicabilidade tanto a romanos como a estrangeiros ${ }^{55}$

Livre de formalidades, regulador do comércio, que se aplicava tanto entre cidadãos romanos como frente ao estrangeiro, o ius gentium não era propriamente um direito universal supranacional, senão direito nacional romano e não especial para regular as relações com os não-romanos. Direito tipicamente romano, vigorava entre os cidadãos e também era acessível ao estrangeiro sem commercium. No terceiro século não se aplicava, por exemplo, em Atenas, no Egito, na Gália ou Espanha: era aplicado unicamente pelo pretor (urbano e peregrino) no âmbito de sua jurisdição. Era romana, portanto, sua produção, bem como sua configuração e aplicação: somente os sujeitos a quem se aplicava podiam ser outros que nãoromanos.

Estas normas foram chamadas "direito das gentes" (dos povos) porque os romanos, ao menos os antigos, não podiam aceitar, nem reger-se por um direito estrangeiro. Do mesmo modo que assimilaram os deuses germânicos aos seus, sem violentar suas convicções religiosas (interpretatio Romana), consideraram o direito de outros povos do ponto de vista romano. Por esta técnica lhes foi possível, por exemplo, verem refletidos seus negócios

consensuais nos correspondentes contratos de qualquer outro direito estranho, e estimá-lo, apesar de todas as suas características diferenciais, como ius gentium.

Os filósofos romanos, influenciados pela Grécia, tiveram outro conceito do ius gentiume o chamaram de ius naturale, desligando-o totalmente do ordenamento jurídico positivo e entendendo por ele o conjunto de preceitos jurídicos e éticos ditados pela Natureza para todos os homens e povos. Especularam com a idéia de que as instituições aplicáveis aos peregrinos procediam do ius gentium, porém a consideração de que todos os homens nascem livres por natureza fez com que o direito das gentes, em algum momento, não se identificasse com o direito natural.

Cícero, por exemplo, dá a entender que o ius gentium é civil, mas nem todo o direito civil é "das gentes", e acaba por não os distinguir. Por conseguinte, de acordo com Kunkel, "é nesta concepção que ius gentium significa direito supra nacional cosmopolita, próprio de toda a Humanidade, quer dizer um direito que, diferentemente do ius gentium positivo romano, somente tem existência no campo da abstração filosófica." ${ }^{66}$ Desde este ponto de vista filosófico, o direito não é invenção humana, porque provém da lei natural, que é o que razão manda ou proíbe. Daí que se o direito positivo for oposto à reta razão que vem da natureza, carece de validez. O que Cïcero afirma é o vínculo de sociedade entre os homens e os deuses, bem como ser o fim essencial da comunidade política a realização da Justiça, isto é, da ordenada convivência humana. ${ }^{57}$

${ }^{55}$ PUGLIESE, Giovanni. Instituzioni di Diritto Romano. $3{ }^{*}$ ed. Turim: Giappichelli, p. 40

${ }^{56}$ KUNKEL, (nota 8), p. 85

${ }^{57}$ Cf. D'ORS, (nota 1), pp. 31/32; TRUYOL E SERRA,Antonio. Historia de la Filosofia del Derecho y del Estado. 11' ed., vol. I. Madrid: Alianza Editorial, 1992, pp. 190 e ss.

Revista da Faculdade de Direito da UFRGS, v. 21, Março/2002 
Os jurisconsultos imperiais, com base na filosofia ciceroniana, distinguiram três gêneros de direito: o ius civile, como direito próprio dos cidadãos romanos, o ius gentium $\mathrm{e}$ o ius naturale, mas esta última distinção não era tão clara (D.1.1.1.2). Para Ulpiano, por exemplo (D. 1.1.1.4), direito natural era aquele que a Natureza deu a todos os animais; direito das gentes, o direito de relações, aquele observado por todos os povos, análogo ao justo natural aristotélico. Já para Gaio (1.1), ius gentium é o que a razão natural ensina aos homens, e ius gentium, a concreção do ius naturale. A conjugação da tradição filosófica grega com a tradição jurídico-positiva romana explica esta confusão. De qualquer modo, a noção de ius gentium que foi transmitida à posteridade é aquela que o vê como um direito positivo, sancionado pelo uso comum. ${ }^{58}$

\section{Conclusão}

A estrutura da ordem jurídica romana repousa em três níveis delimitados, de modo que a criação, interpretação e aplicação do direito foi obra do legislador, do prudente e do magistrado: a lei e as demais fontes estatais, a interpretatio prudentium e os meios processuais (as ações da lei, o processo formulário e a cognição extraordinária) formam a base da vida jurídica romana, garantindo a cidade contra o arbítrio e o despotismo, pois o legislador estava limitado pela atividade dos intérpretes (prudentes) e aplicadores (magistrado e juiz) e pelo comportamento dos cidadãos (mores maiorum)

Em síntese, o desenvolvimento formulação do direito privado clássico se deu a partir da tensão entre a lex e a recepção pelo comportamento: ao povo era atribuída a criação do direito não só pela lex, mas, fundamentalmente, pela recepção moribus (pelos mores), que dava estabilidade à lex e que incluía a interpretação dos prudentes; de parte do pretor, o direito era criado no edito e, respectivamente, com odicere ius relativamente ao caso concreto.

Os juristas romanos, aptos para descobrir as razões de decidir de cada caso, utilizaram os resultados de sua técnica (arte) na construção de uma ciência assente num conhecimento verdadeiro e válido e num conhecimento sistematizado (ainda que fosse limitado o seu interesse sistemático) em um catálogo de regras e princípios. Avessos às abstrações, os jurisconsultos romanos se orientavam genericamente para o direito das ações e não para o direito processual, porque se limitavam, na maior parte dos casos, a interpretar o meios judiciais propostos no edito, especialmente, da ações. Assim, expunham os pressupostos que deveriam existir para que $o$ magistrado pusesse à disposição as ações, o resultado que se poderia alcançar por meio delas, e faziam propostas a propósito da redação de novas fórmulas, principalmente das ações úteis (actiones utiles). Esta orientação ao regime das ações não foi abandonada nem sequer na época pós-clássica e nem na compilação justinianéia. Isto não quer dizer, contudo, que não existissem partes do ordenamento que a jurisprudência não expusesse do ponto de vista das ações: basta ver as doutrinas desenvolvidas sobre a aquisição da propriedade, sobre o regime da stipulatio, a aquisição e perda da patria potestas, o testamento, etc. O que se afirma é a sua resistência a fixar conceitos jurídicos. Tanto é assim que, para muitos conceitos importantes os romanos não tiveram uma expressão técnica (persona, negócio jurídico, declaração de vontade); por outro lado, para diferentes conceitos existia termo técnica mas faltava uma definição e, nos casos em que estas existem, estão imperfeitamente construídas ou são pós-clássicas.
Além disso, os prudentes tiveram a tendência de sintonizar os resultados de seu saber com as exigências da justiça, mais especificamente da justiça material particular para a geral, de forma que a utilidade geral prevalecesse sobre a justiça particular. Experiência metodologicamente qualificada, a noção de ius que permeia toda a experiência jurídica romana é a de arte que faz prevalecer um fundamental critério de valoração e este deve ser a inspiração constante do operador do direito. Este critério fundamental é a racionalidade conjugada com a igualdade porque o jurista, atento aos dados da realidade, tem em conta o ineliminável papel que compete ao homem na realização do bonum et aequum. O ius não é, via de conseqüência, o dever-ser estatal.

O maior mérito dos jurisconsultos romanos, no entanto, foi transformar o rígido ius civile em um sistema flexível, capaz de converter-se no direito comum a um império multinacional e, mais além de seu âmbito temporal, no direito de toda uma orbe cultural. A aceitação de um direito fundado na comum natureza racional humana - na humanitas - deu lugar a um aperfeiçoamento progressivo do direito positivo, constituindo um critério valorativo fundamental para a produção, interpretação a aplicação de todo o direito.

Assim, a partir do uso constante das noções de equidade (aequitas) e fides, a missão dos juristas foi enaltecida e ganhou um sentido moral, de forma que o principio da boa-fé emergiu como princípio cardinal de todo o ordenamento jurídico, especialmente no campo negocial.

Por tudo isto, o estudo do ius romanum fornece ao jurista atual uma firmeza de princípios perante as transformações da vida jurídica, pois, em última instância, o grande êxito do direito romano foi ter conciliado os princípios tradicionalmente consagrados com as novas exigências da vida, por meio de uma técnica rigorosa. $\mathrm{O}$ direito romano clássico também pode fundamentar a ciência do direito comparado, por ser a raiz comum de vários direitos românicos; mais do que isso, em tempos de formação de blocos socioeconômicos, em que a unificação do direito privado pela via legislativa é inviável (senão impossível), o estudo do ius romanum é método idôneo para fins de unificação, pois, a partir dele, pode-se formar uma doutrina comum e se fortalecer a consciência dos juristas no que diz respeito a sua autonomia e liberdade.

${ }^{58}$ Cf. TRUYOL E SERRA, (nota), p. 195. 